\title{
Algumas observações sobre a noção aristotélica de prioridade em natureza e em substância
}

Michail Peramatzis

Queen's College (Belfast)/Christ Church College (0xford)

michail.peramatzis@philosophy.ox.ac.uk

resumo A noção de prioridade em natureza e em substância, que Aristóteles introduz em Metafísica 1019a2-4, tem sido tradicionalmente interpretada em termos de prioridade em existência: $x$ é anterior a y se $x$ pode existir sem y, mas y não pode existir sem que $x$ exista. Neste artigo, contesto a interpretação tradicional e argumento em favor de uma alternativa, em termos de prioridade no ser: $\mathrm{x}$ é anterior a y se $\mathrm{x}$ pode ser o que $\mathrm{x}$ é sem que y seja aquilo que y é, mas não inversamente, y não pode ser o que y é sem que $x$ seja quilo que $x$ é. Essa noção de prioridade no ser é o correlato ontológico da prioridade definicional. palavras-chave Prioridade; ontologia; essencialismo; substância; modalidade; definição

Em Metafísica $\Delta .11$ Aristóteles introduz sua noção de prioridade em natureza e em substância (a qual, por brevidade, chamarei de 'prioridade ontológica') e a formula em termos da seguinte Asserção de Independência:

[AI] A é ontologicamente anterior a B somente se A pode ser ("einai") sem B mas B não pode ser sem A (ver [T1]-[A]).

[T1] Met. $\Delta .11,1019 a 1-4:$ [A] Algumas coisas são chamadas anteriores e posteriores dessa maneira, outras são chamadas assim em natureza e em substância, aquelas para as quais é possível ser [“einai"] sem outras coisas, mas não as últimas sem elas; essa divisão foi usada por Platão.

Virtualmente, todos os comentadores importantes da Metafísica de Aristóteles formulam [AI] ou outras postulações equivalentes feitas em 
outras passagens do corpus como o que Kit Fine denomina 'modo existencial-modal' de entender a noção de independência ontológica:

[PE] A é ontologicamente anterior a B se e somente se A pode existir sem $\mathrm{B}$ existir mas não inversamente [Prioridade quanto à Existência]. Eu gostaria de discutir e, em grande medida, enfraquecer essa linha de interpretação. Minha principal preocupação aqui não é examinar em detalhe se as noções modais de necessidade ou possibilidade são ou não uma parte fundamental ou indispensável da acepção aristotélica de prioridade $^{1}$. Em contrapartida, pretendo criticar o alegado aspecto existencial desse ponto de vista.

Eis os problemas que surgem de [PE]:

(a) O próprio Aristóteles entende a prioridade ontológica Platônica do modo [PE], como uma independência existencial assimétrica das Formas com respeito a todas as suas instâncias sensíveis. De fato, ele frequentemente critica e condena a posição Platônica de que as Formas podem existir sem que algum sensível exista, mas não inversamente. Se se assumir que seus candidatos preferidos para a substancialidade primeira, suas formas substanciais, satisfazem o critério da prioridade ontológica, resulta implausível pretender que elas seriam ontologicamente anteriores do modo [PE], exatamente da mesma maneira Platônica que Aristóteles considera problemática. Seguramente, há quem pense que as formas aristotélicas seriam anteriores, não ontologicamente, mas apenas quanto à definição ou explicação, ao passo que somente os compostos particulares, as substâncias primeiras das Categorias, seriam ontologicamente anteriores em existência. Deixo essa opinião para discutir mais tarde.

Há uma outra razão para pensar que a prioridade ontológica aristotélica não é a prioridade existencial platônica. Quando Aristóteles discute a prioridade platônica, ele não usa o termo "einai" (como faz em [T1]-[A]). Antes, ele usa termos mais fortes, que implicam uma destruição ou uma eliminação da existência: “anaireisthai”. Por exemplo, em EE., 1217b10-12, [T2]-[D]:

[T2] EE. 1217b2-15: [A] Pois eles dizem que o Bem-ele mesmo é a melhor coisa de todas, e o Bem-ele-mesmo é aquilo a que pertence ser tanto o primeiro dentre os bens [prôton einai tôn agathôn] quanto a 
causa, por sua presença, de serem boas as outras coisas. [B] E ambos estes pertencem à forma do Bem. Por 'a ambos' eu quero dizer o fato de que ele é o primeiro dos bens [prôton tôn agathôn], e de que ele é causa, por sua presença, das outras coisas serem boas. [C] Pois eles dizem que é sobretudo daquele objeto [a forma do Bem] que o bem é verdadeiramente dito (outras coisas sendo bens por participar nela, e se assemelharem a ela), e [D] ele é primeiro dentre os bens; pois, se o objeto no qual as coisas participam fosse eliminado, com ele o seriam todas as coisas que participam na Forma, e são ditas o que são por participarem nela; e é desse modo que o primeiro está com relação ao posterior. [E] Então, o Bem-ele-mesmo é a Forma do Bem; [F] e de fato, como as outras Formas, ele é separado das coisas que participam nele; tradução de Woods, com pequenas alterações].

Aristóteles sustenta que, se uma Forma platônica é destruída, suas instâncias sensíveis também são destruídas: "anairoumenou gar tou metechomenou anaireisthai kai ta metechonta tês ideas, ha legetai tôi metechein ekeinês". Igualmente, em Met. $\Delta .8,1017 \mathrm{~b} 18-21$, se os objetos matemáticos ou números são 'eliminados', todas as coisas também são eliminadas, pois os objetos matemáticos ou números são as partes definitórias de todas as coisas: "hôn anairoumenôn anaireitai to holon" e para o número: "anairoumenou te gar ouden einai, kai horizein panta". Essas formulações sugerem que, conquanto a explicação de Aristóteles para a prioridade platônica atribua uma independência existencial assimétrica às Formas, seu próprio ponto de vista não precisa ser tomado nesse sentido estrito. Ele pode ser algo distinto de ou mais liberal que a prioridade existencial platônica.

(b) Sob o esquema existencial, os exemplos oferecidos em várias passagens cruciais da Metafisica tornam-se enganosos ou incorretos. Pois em alguns casos os itens pretensamente anteriores não podem existir em ato sem que existam os posteriores. Em outros casos, embora a prioridade ontológica exija uma relação assimétrica de independência ontológica, itens anteriores e posteriores podem (ou não) existir independentemente um do outro (não-simetricamente).

Assim, por exemplo, em [T3], a pretensão de que um ângulo reto seja ontologicamente anterior a um agudo causou muitos problemas aos comentadores. 
[T3] Met. Z.10, 1034b28-32: Além disso, se as partes são anteriores ao todo, então, visto que um ângulo agudo é parte de um ângulo reto, e visto que um dedo é parte de um [certo tipo de] animal, o ângulo agudo será anterior ao ângulo reto, e o dedo ao homem. Mas o inverso manifesta-se ser o caso; pois, quanto à explicação, os primeiros são definidos em termos dos últimos, e os últimos são anteriores por serem sem os primeiros [tôi einai aneu allêlôn] (tradução de Bostock com alterações).

A dificuldade surge porque comentadores constróem esse tipo de relação de prioridade ontológica do modo existencial. Consequentemente, eles veem Aristóteles como incorrendo em um erro óbvio: um ângulo reto pode ser definido independentemente de um ângulo agudo (mas não inversamente), mas não pode existir como tal sem que o ângulo agudo exista como uma de suas partes. Pois, se uma de suas partes for extraída, um ângulo reto não existirá, mas, presumivelmente, será substituído pelo ângulo agudo restante. Inversamente, não há razão para negar que um ângulo agudo possa existir sem que um ângulo reto exista.

O caso dos ângulos reto-agudo é semelhante ao exemplo do todo-eparte relativamente à linha em [T1]-[C]. Aristóteles assume que

Uma linha inteira, L, é anterior a uma meia-linha, 1/2 L (um segmento que é metade de uma linha inteira).

Contudo, ao passo que uma meia-linha pode existir sem uma linha inteira, uma linha inteira não pode existir sem que exista alguma de suas metades. Pois sem esta, uma linha inteira cessaria de existir como tal, e daria seu lugar ao meio-segmento restante.

Poderia ser objetado que, em [T3] e [T4]-[A], o esquema existencial parece funcionar no caso dedo-homem: um homem pode existir independentemente de seu dedo existir, mas um dedo não pode existir (como um dedo plenamente funcional) sem que um homem exista. Contudo, [PE] parece falhar mesmo nesse exemplo, visto que não torna a relação de prioridade ontológica assimétrica. Um ser humano plenamente funcional e completo não pode existir (como plenamente funcional ou completo) sem que seu dedo exista: pois sem seu dedo, ele ou ela não seria completo, mas mutilado. Inversamente, um dedo plenamente funcional não pode existir (como plenamente-funcional) se destacado de um ser humano. 
Além disso, assim como um ser humano mutilado pode existir (como mutilado) sem seu dedo destacado, assim também seu dedo destacado e não funcional pode existir (como destacado e não-funcional) sem o correspondente ser humano mutilado. De fato, a noção de [PE] é problemática independentemente de nosso exemplo ou escolha.

(c) Aristóteles argumenta que as formas substanciais são substâncias primeiras. Então, elas têm que satisfazer o requisito de prioridade ontológica: elas seriam ontologicamente anteriores a, por exemplo, os compostos particulares ou aos tipos de matéria que elas en-formam. Dado [PE], no entanto, as formas falham em satisfazer esse critério: pois elas não podem existir sem que exista algum composto en-formado ou certos tipos de matéria. Por exemplo, como aristotélicos, poderíamos pretender que uma casa completa - realizando plenamente a forma ou a função de uma casa - seja, em algum sentido ontológico relevante, anterior a, por exemplo, os tijolos que a constituem. Contudo, em se adotando a abordagem existencial, será preciso explicar de que modo a casa completa poderia existir sem os tijolos existirem, ao passo que os últimos não poderiam existir sem a primeira. Eis uma tarefa difícil, visto que os tijolos podem ou efetivamente existem sem ou antes da casa completa existir, mas a recíproca não se dá. Uma objeção possível a esta altura poderia ser a seguinte: a casa poderia existir sem estes tijolos ou materiais particulares, ainda que ela não possa existir sem quaisquer tijolos ou materiais em geral. Contudo, nesse caso, não há assimetria: assim como a casa pode existir sem esses materiais, assim também os últimos podem existir sem a casa.

(d) Mais importante, uma essência ou forma F sequer é o tipo de entidade que poderia existir independentemente dos compostos particulares de certos tipos de matéria, os objetos dos quais ela é forma ou essência. Uma essência F não é ela própria um objeto mas um modo de ser essencial para os objetos dos quais ela é essência. Isso, penso, é parte da razão pela qual Aristóteles usa o termo técnico 'o-que-é-para-algo-ser-F', ou locuções semelhantes, para essência: to einai hekastôi (ver, por exemplo, Met.Z.4, 1029b20). De fato, F não é o tipo de entidade que poderia existir independentemente de outros itens ou por si mesma.

Além do mais, no mundo sublunar aristotélico, uma forma substancial é uma entidade que essencialmente ou necessariamente (qualquer 
modalidade servirá para os propósitos presentes) en-forma certos tipos de matéria ou compostos. Sendo assim, uma entidade desse tipo não poderia existir independentemente de que existam certos tipos de matéria ou sem os compostos que ela en-forma.

Em virtude desses problemas, eu gostaria de argumentar em favor de um entendimento alternativo da prioridade ontológica aristotélica:

[PS] A é ontologicamente anterior a B se e somente se A pode ser o que A é independentemente de B ser o que B é, ao passo que a recíproca não é o caso [Prioridade quanto a Ser o que algo é].

Eis como exponho minha compreensão de [PS]: trata-se de uma noção não-existencial de prioridade ontológica que pode ser formulada como o correlato ontológico de, ou a contraparte real para, a prioridade quanto à definição. $\mathrm{O}$ próprio Aristóteles assume que $\mathrm{A}$ é anterior a $\mathrm{B}$ quanto à explicação ou definição apenas no caso em que (a definição de) A está incluída na definição de B mas não inversamente (para evidência textual, ver [T3], Met. Z.10, 1034b30-32; [T4]-[A], Met. Z.10, 1035b4-11; [T5][A], Met. M.2, 1077b3-4). Subjacente a [PS], então, está a idéia de que há uma "correspondência" entre os níveis de definição e realidade. A noção crucial subjacente à prioridade quanto à definição é a de ser definido como ou ser entendido em termos de algum conceito mais básico, uma noção formalmente representada pela relação de inclusão de (a definição de) um certo item na definição de outro item. A idéia subjacente a [PS] é que uma entidade ontológica básica, seu ser o que ela é, é a parte fundamental do que é ser uma entidade posterior ou dependente: pois ela torna uma entidade desse tipo aquilo que ela é. Um exemplo é: embora uma casa completa não possa existir sem os tijolos que a constituem, no entanto, o que os tijolos são - isto é, uma casa completa - depende do que é ser (o formato ou função de) uma casa completa, mas não viceversa. Essa idéia de [PS] é inspirada por, e é semelhante a, o próprio modo como Kit Fine entende dependência e independência ontológica. Kit Fine esclarece sua acepção de dependência ontológica assim: “A noção de um objeto dependente de outro é, portanto, a contraparte real da noção nominal de um termo ser definível em termos de outro" ("Dependence”, p. 275). Ele então reconhece as origens aristotélicas dessa idéia, que faz remontar aos Tópicos Z.4 and Met.Z.1, 1028a35-36 (pp. 275-6). 
Eu gostaria de observar, a esta altura, que [PS] é um modo tão legítimo de entender a prioridade ontológica e de [AI] quanto [PE]. Pois o "einai" em [AI] pode ser tomado seja existencialmente seja como significando "ser o que algo é". Eu gostaria de enfatizar, contudo, que, do meu ponto de vista, o argumento de Aristóteles como um todo, bem como seus respectivos exemplos, sugere que sua noção de prioridade ontológica só funciona bem se a abordagem existencial é recusada e substituída por uma interpretação em termos de ser o que algo é.

Para esclarecer ainda mais [PS], eu levantaria esta objeção: acaso minha noção de [PS] não seria meramente uma noção disfarçada ou exagerada de prioridade quanto à definição (nominal, linguística, ou conceitual)?

Minha resposta é que não, e que a razão básica para ela é que as formas não são meramente objetos abstratos ou itens linguísticos-definicionais. Primeiro, uma evidência textual:

[T4] indica que Aristóteles toma as formas substanciais não meramente como itens abstratos ou linguísticos, mas como entidades fundamentais, itens do mundo real. Isso implica que, no caso das formas, ele busca estabelecer a prioridade ontológica para além da prioridade quanto à definição. Que a prioridade quanto à definição se aplica a formas em relação a partes materiais é claro por [T4]-[A]. O argumento apresentado em [T4]-[B] também parece sustentar a prioridade ontológica das formas em relação às partes materiais e os compostos. ${ }^{2}$ [T4] Met. Z.10, 1035b4-14: [A] As partes da fórmula, nas quais a fórmula é dividida, são anteriores - algumas delas ou todas elas; e a fórmula do ângulo reto não é dividida na fórmula do agudo, mas a do agudo na do reto; pois quem define o ângulo agudo usa o reto; pois o agudo é o menor que o reto. E, igualmente no caso do círculo e do semicírculo; pois o semicírculo é definido pelo círculo, e o dedo pelo todo; pois o dedo é tal-e-tal parte do homem. [B] De fato, são posteriores as partes materiais e nas quais uma coisa é dividida como em matéria; mas as que são partes da fórmula e da substância que é conforme a fórmula [tês ousias tês kata ton logon] são anteriores algumas ou todas elas.

Aristóteles sustenta que há uma substância, a forma, que corresponde à explicação ou fórmula, e que é anterior aos compostos dos quais ela é 
substância ou forma (1035b13-15;18-21). Isso claramente favorece a idéia de uma correspondência entre os níveis definicional e ontológico. A frase "hê kata ton logon ousia" (b13; 15) sugere que o que ocorre no nível linguístico ou da definição é o correlato do que há no nível da realidade.

Em [T4]-[C]:

[T4]-[C] Ora, visto que a alma dos animais (pois é ela a substância do animado) é a substância conforme à fórmula "hê kata ton logon ousia" isto é, a forma e o-que-é-ser tal corpo "to eidos kai to ti ên einai tôi toiôde sômati" (ao menos, se cada parte é adequadamente definida, ela não pode ser definida sem sua função, a qual ela não pode ter sem a percepção sensível), segue-se que as partes da alma são anteriores algumas ou todas elas - ao composto animal como um todo, e igualmente nos casos particulares, enquanto o corpo e suas partes são posteriores a essa substância [...] (tradução de Bostock com alterações).

O tipo de substância que corresponde à explicação é, no caso dos seres vivos, sua alma (1035b14-16). Almas, no entanto, não são itens meramente linguísticos ou definitórios, mas princípios organizadores do mundo real, que fazem dos seres vivos o que eles são (1035b16: "to eidos kai to ti ên einai tôi toiôde sômati”). Isso implica que -em adição à prioridade quanto à definição - as formas satisfazem um tipo de prioridade ontológico, [PS], relativo a seres animados. Se isso é correto, o tipo de prioridade e posterioridade sob discussão (1035b18-19;20-21) tem que ser ontológico: pois Aristóteles estaria interessado não apenas em relações definicionais (1035b16-18) mas também em relações entre compostos vivos e suas almas (b18-21). As afirmações entre parênteses em b16-18, [T4]-[C] não podem implicar que Aristóteles esteja preocupado somente com considerações definicionais, na medida em que estas últimas não poderiam contribuir para relações ontológicas relevantes entre os seres vivos e suas almas. Antes que isso, essas observações parentéticas sugerem que teses ontológicas podem ser entendidas com base em afirmações definitórias correspondentes. Assim sendo, deve haver um correlato ontológico da prioridade quanto à definição, isto é, [PS], o qual faz com que as formas se qualifiquem como substâncias genuínas, e não meramente como itens definitórios ou linguísticos. Esse tipo de prioridade de 
uma forma em relação aos tipos de matéria e compostos que ela enforma é ontológico: uma forma torna os que sob ela se subsumem aquilo que eles são (b16). Sem uma forma, a matéria e as partes materiais são apenas seres potenciais, incompletos, e não substâncias compostas plenamente funcionais em ato ou suas partes funcionais. Além disso, um composto faz-se o tipo de coisas que é pelo tipo relevante de forma, mas a recíproca não é o caso.

Que Aristóteles, muito geralmente, faça a distinção entre prioridade quanto à definição e ontológica fica claro em [T5]-[A], Metafísica M.2 (1077a36-b11). O contexto dessa passagem é uma discussão das posições metafísicas que tomam os objetos matemáticos como substâncias primeiras em relação aos corpos naturais perceptíveis (1077a14-20; 2436). Aristóteles ataca esse ponto de vista tecendo uma distinção entre prioridade quanto à definição e prioridade quanto à substância:

[T5] [A] Sejam [os objetos matemáticos] anteriores quanto à explicação, porém, nem tudo que é anterior quanto à explicação é também anterior quanto à substância. Pois são anteriores quanto à substância [a alguns outros itens] as coisas que, se separadas, ultrapassam quanto ao ser [os outros itens], e as coisas são anteriores quanto à explicação aos itens cujas explicações são constituídas das explicações das primeiras; e essas não se dão ao mesmo tempo [tauta de ouch hama hyparchei].

Essa passagem não apenas traça a distinção entre prioridade quanto à definição (tôi logôi) e ontológica (têi ousiai). Mais importante, ela claramente estabelece que a prioridade quanto à definição, por si mesma, não acarreta automaticamente a prioridade ontológica. De fato, se minha compreensão de prioridade ontológica é correta, [PS] poderia ser distinguido de prioridade quanto à definição.

É claro que a formulação de prioridade ontológica oferecida nessa passagem é (no mínimo) consistente com minha compreensão de [PS]. Aristóteles sustenta que A é ontologicamente anterior a B somente se A é (i) separado de B e (ii) ultrapassa B quanto ao ser. A condição (i), a noção de separação, pode ser entendida como uma relação não simétrica de independência que é uma condição necessária para a prioridade. Se assim é, a condição (i) estabelece simplesmente que A é, ou pode ser, sem 
(aneu ou choriston tou) B, e então A é separado de B. A seu turno, a condição (ii) acrescenta a requerida assimetria que, juntamente com a separação, produz a prioridade ontológica: na medida em que A ultrapassa B quanto ao ser (pois A é ou pode ser separado de B), B é ultrapassado por A quanto ao ser, porque ele não é ou não pode ser separado de A. Isso é virtualmente equivalente à formulação de [AI] em [T1]-[A] (Met. $\Delta .11$, 1019a3-4), em que um item anterior A é dito ser aneu ou sem o posterior $\mathrm{B}$, mas não vice-versa. Mais importante, a qualificação tôi einai (1077b3) concorda com a formulação aristotélica de prioridade ontológica em termos de einai em [T1]-[A]. Consequentemente, assim como em Met. $\Delta .11$, assim também em M.2, a noção de prioridade ontológica é neutra com respeito a [PE] e [PS]. No entanto, pelos meus argumentos parece claro que [PS] resulta ser melhor que [PE] como compreensão da prioridade ontológica aristotélica. Se esses argumentos são plausíveis, a noção de prioridade ontológica em M.2 deveria ser interpretada em termos de [PS].

Para os presentes propósitos, contudo, não é necessário mostrar que a formulação de Metafísica M.2 ampara [PS] plenamente. A objeção à distinção entre prioridade quanto à definição e prioridade ontológica já pode ser evitada meramente se essa formulação for consistente com [PS], como sustentei logo acima. Pois o próprio Aristóteles continua a sustentar que a prioridade ontológica (como especificada em Metafísica M.2) não é implicada pela prioridade quanto à definição. Ora, se é assim, tampouco [PS] é implicada pela prioridade quanto à definição: pois, se [PS] fosse implicada pela prioridade quanto à definição, não seria consistente com a prioridade ontológica em M.2 (como certamente parece ser). Se isso é correto, a força da objeção reduz-se significativamente. A noção de [PS] não é a mesma que de prioridade quanto à definição, porque esta não necessariamente acarreta a primeira. Aristóteles argumenta da seguinte maneira:

(a) Nem tudo que é anterior quanto à definição o é também ontologicamente (b1-2).

Essa importante asserção evita que a prioridade quanto à definição acarrete a ontológica, e ainda permanece compatível com a seguinte tese:

(b) Há algumas coisas que são anteriores quanto à definição bem como ontologicamente. 
É crucial para o ponto de vista de Aristóteles (e para minha interpretação de seu ponto de vista) argumentar em favor de (b). Pois, mesmo que a prioridade quanto à definição não seja o mesmo que [PS], [PS] será o correlato ontológico de prioridade quanto à definição. Assim sendo, as entidades que são ontologicamente básicas e satisfazem [PS] devem também ser básicas quanto à definição e satisfazer o requisito de prioridade quanto à definição. De fato, no caso específico dessas entidades, a implicação da prioridade ontológica (concebida como [PS]) a partir da prioridade quanto à definição parece se dar: pois seu modo específico de ser anterior quanto à definição deveria implicar que eles também são ontologicamente anteriores consoante [PS]. Claro que, do ponto de vista de Aristóteles, as entidades ontologicamente fundamentais que possuem ambos os tipos de prioridade devem ser formas substanciais: pois elas não apenas são definidas independentemente de certos tipos de matéria e compostos particulares (mas não inversamente), mas também tornam essas entidades dependentes aquilo que elas são. A combinação de (a) e (b), então, proporciona a negação da objeção em pauta: conquanto a prioridade definicional seja distinta de [PS], as duas noções não são mutuamente excludentes.

Para corroborar (b), no entanto, devemos examinar a frase "tauta de ouch hama hyparchei” em 1077b4. Para torná-la compatível com (a) e (b), Julia Annas acrescenta, com Bywater, um "aei" depois de "hyparchei"3. Ross julga isso desnecessário: pois (como ele sustenta) a frase "tauta de ouch hama hyparchei" não requer que os dois tipos de prioridade nunca devam pertencer à mesma coisa, mas apenas implica que (no mínimo) eles nem sempre se aplicam à mesma coisa ${ }^{4}$. Concordo com Ross pelas seguintes razões. Primeiro, sua construção torna 1077b4 consistente com b1-2 sem envolver qualquer correção textual. Segundo, há outras passagens fora de Metafísica M.2 em que Aristóteles de fato argumenta que certos itens são anteriores tanto quanto à definição quanto com respeito ao ser. Por exemplo, [T3], Met.Z.10, 1034b28-32, fornece exemplos de itens que são anteriores tanto tôi logôi quanto tôi einai. E, terceiro, o hama usado em 1077b4 não necessita ter um sentido temporal estrito. Ele não precisa ser entendido como implicando que os dois tipos de prioridade não pertencem à mesma coisa ao mesmo tempo, uma exigência que pode acarretar que, quando algo é anterior de uma 
maneira, ele não pode ser anterior da outra. A frase adverbial ouch hama em Aristóteles tem sempre um sentido lógico de não-universalidade (caso em que ela seria conceitualmente próxima do ou panta em b1-2) ou não-implicação entre duas noções 5 . Se assim é, a afirmação de que 'essas duas noções não se dão hama' pode sugerir simplesmente que prioridade quanto à definição não acarreta automática ou necessariamente prioridade ontológica.

À luz dessas considerações, parece plausível concluir que há uma distinção genuína entre prioridade quanto à definição e prioridade ontológica, mesmo se a última for tomada como [PS]. Embora essa conclusão enfraqueça o caráter decisivo da objeção que estamos considerando, uma outra questão poderia ser levantada sobre se e o que estaria dentro do escopo de (b): seria verdade que as formas substanciais aristotélicas se contariam entre aquelas entidades que possuem ambos os tipos de prioridade relativamente a certos itens? Com efeito, poderia ser argumentado que a passagem Metafísica M.2 citada logo acima -ver [T5]$[\mathrm{B}]-$ indicaria que, enquanto as formas seriam anteriores apenas quanto à definição, mas não ontologicamente, apenas os compostos particulares seriam ontologicamente anteriories a certos itens.

[T5]-[B] Pois, se os atributos não são para além das substâncias [ei gar mie esti ta pathê para tês ousias], como, por exemplo, aquilo que é móvel ou é branco, branco é anterior a homem branco quanto à explicação, mas não quanto à substância [to leukon proteron kata ton logon all' ou kata tên ousian]; pois não é possível ser separado, mas é sempre conjuntamente com o composto (e chamo 'composto' o homem branco), então é claro que nem o que é por abstração é primeiro, nem o que é por acréscimo é posterior; pois homem branco é dito por acréscimo a branco [1077a36b11; tradução de Annas com pequenas alterações].

De fato, por exemplo, as formas podem ser vistas do mesmo modo que os exemplos dos objetos matemáticos ou atributos acidentais de M.2 (1077b5: pathê). Em 1077b5-9, os exemplos de Aristóteles sugerem que atributos acidentais, tais como ser branco ou ser em movimento, podem ser definidos independentemente dos compostos aos quais pertencem (mas não inversamente), mas não são ontologicamente anteriores a eles (ou kata tên ousian). Por exemplo, a especificação de "branco" não inclui 
"homem branco", termo que se refere ao composto consistente em um homem particular que é branco. Inversamente, no entanto, a caracterização de "homem branco" tem que envolver "branco" ou a especificação de "branco": pois branco é uma parte da fórmula "homem branco". Por outro lado, o atributo de ser branco não é ontologicamente anterior a um homem particular que é branco se (como observa Aristóteles) ele não é nada para além de uma substância particular desse tipo (1077b4-5: ei gar mie esti ta pathê para tês ousias). Ou o que é o mesmo: ser branco não pode ser separado de, mas é sempre conjuntamente com, um ou outro composto, um homem particular do qual ser branco é atributo (b7-8: ou gar endechetai einai kechorismenon all' aei hama tôi sunolôi estin). Ou seja, atributos acidentais, como ser branco, não podem sequer satisfazer a condição de separação, (i), da definição de prioridade ontológica oferecida em Met. M.2, [T5]-[A]. Mas, se assim é, como poderiam se qualificar como entidades ontologicamente anteriores relativamente a certos objetos?

O objetor poderia, então, concluir que, porque as formas são semelhantes aos objetos matemáticos ou atributos acidentais, elas são anteriores aos compostos particulares apenas quanto à definição, mas não ontologicamente. De fato, de modo semelhante à conclusão de Aristóteles sobre os atributos acidentais, as formas seriam abstrações em pensamento que não seriam ontologicamente anteriores aos compostos, na medida em que os compostos não são ontologicamente posteriores a elas (1077b9-10: "hôste phaneron hoti oute to ex aphaireseôs proteron oute to ek prostheseôs husteron"). Donde se seguiria a objeção de que compostos particulares seriam ontologicamente anteriores às formas, as quais seriam meras abstrações em pensamento, assim como o são os objetos matemáticos ou os atributos acidentais.

A principal fragilidade inerente a essa linha de argumento é que o objetor assume sem justificação que formas são como os atributos acidentais. No entanto, não há razão obrigando a isso. De fato, parece mais plausível pensar que formas substanciais não são como entidades desse tipo: pois elas não são pathê, seres acidentais ou não-substâncias, mas entidades substanciais, integrantes da essência dos objetos dos quais elas são formas. Claro que o objetor poderia replicar que, mesmo não sendo pathê, elas seriam, contudo, abstrações em pensamento, assim como os objetos matemáticos. Em breve, abordarei essa objeção. 


\section{4}

Agora, porém, é importante mostrar que as afirmações feitas e os exemplos oferecidos em Metafísica M.2, [T5]-[B], não requerem a interpretação proposta por esse tipo de objeção. De fato, Aristóteles não sublinha que atributos acidentais não são 'nada para além das substâncias particulares', ou que elas não podem ser 'separadas de, mas são sempre em conjunto com' compostos. No entanto, ele não afirma que substâncias ou compostos particulares sejam independentes de, ou separados de, atributos acidentais de nenhuma maneira ontológica substantiva. Se assim é, a conclusão do objetor de que substâncias ou compostos particulares são ontologicamente anteriores a atributos acidentais não se segue. Mas isso não deve ser visto como uma falha: Eu já argumentei em outro lugar - e esse ponto pode ser discutido mais tarde (ver Apêndice abaixo) - que a pretensão de substâncias compostas particulares à prioridade ontológica sobre os atrubutos não-substanciais não parece justificada. Pois, independentemente de como podemos entender a natureza da prioridade ontológica, o escopo da relação de prioridade, ou os tipos de relata posteriores, permanece extremamente dificil sustentar a assimetria requerida 6 .

Se isso for correto, o ponto de Aristóteles em [T5]-[B] pode ser simplesmente que atributos acidentais não são ontologicamente independentes de seus portadores. Não é necessário pensar que ele também acredita que compostos particulares são ontologicamente independentes de seus atributos não-substanciais, sendo, assim, ontologicamente anteriores a eles. De fato, sua conclusão em 1077b9-10 poderia ser interpretada como impedindo a inferência final do objetor de que compostos particulares seriam ontologicamente anteriores a seus atributos acidentais. Pois sua afirmação literal veicula o seguinte: nem os atributos acidentais são ontologicamente anteriores nem os compostos são ontologicamente posteriores (oute to ex aphaireseôs proteron oute to ek prostheseôs husteron). Isso não é o mesmo que o ponto de vista de que os compostos seriam anteriores, enquanto os atributos acidentais seriam posteriores. Antes que isso, a conclusão de Aristóteles pode bem implicar que, no caso de atributos acidentais e compostos, prioridade ou posterioridade ontológica não se aplicam em absoluto. A razão para isso poderia ser que no caso deles não há expectativa de assimetria; ou que os dois tipos de entidades são ontologicamente interdependentes. De qualquer maneira, parece plausível pensar que Aristóteles pode estar excluindo os compostos e seus atribu- 
tos acidentais do domínio da prioridade ontológica. No entanto, ainda que seja assim, seria um erro concluir a partir dessa afirmação (do modo como faz a objeção em discussão) que somente substâncias compostas particulares seriam ontologicamente anteriores, ao passo que as formas poderiam ser anteriores apenas definicionalmente a certos itens. Por tudo o que ele diz, compostos particulares podem permanecer completamente fora do domínio da relação de prioridade ontológica.

Além disso, há outra vantagem conceitual no meu ponto de vista. Não apenas a noção de prioridade 'em ser o que algo é' é claramente distinguida do critério da prioridade definicional. Mais importante ainda, ela chancela esse critério definicional ao sustentar uma noção de prioridade definicional real, por oposição a nominal, linguística ou conceitual. A prioridade definicional, por si mesma, não pode distinguir definições reais de nominais (por exemplo, definições de não-existentes). Um ser humano é definido como, por exemplo, um animal com um certo tipo de alma, ao passo que um bode-cervo é definido como a prole de um bode e um cervo. Apenas pelo critério da prioridade definicional, assim como a noção de uma alma de um certo tipo é anterior àquela de um homem, a noção de uma prole de bode-e-cervo é anterior a um bodecervo. Disso não deve se seguir, contudo, que um bode-cervo seja o tipo de entidade que tem uma definição real ou seja en-formado por uma forma substancial real do mundo. A noção de [PS] serve como um expediente para impedir esse tipo de inferência. Pois o que assegura a "realidade" das definições de certos tipos de objetos é que os itens referidos no definiens são entidades do mundo real que tornam os objetos definidos o que eles são. Isso não se dá no caso de definições meramente nominais, visto que as fórmulas definitórias não necessitam corresponder a qualquer entidade do mundo real que torne os objetos o que eles são.

Deve estar mais claro agora por que formas substanciais não devem ser concebidas como meramente anteriores quanto à definição, ou como abstrações em pensamento, tal como são os objetos matemáticos. A base subjacente à noção de [PS] é que as formas são substâncias primeiras, entidades ontologicamente fundamentais do mundo real. Por essa razão, uma forma é o referente de um definiens real, quer dizer, um item linguístico (não-proposicional) incluído na fórmula definitória de um certo tipo de objeto. Igualmente, as formas - seu ser do modo como são, 
por oposição à sua mera existência - constituem o que confere verdade, por assim dizer, às definições reais (proposicionais) de certos tipos de objetos. Essas duas últimas afirmações chancelam os fatos de que um definiens real é um item linguístico que efetivamente tem referência e que uma definição real é "verdadeira" ou correta. Correlativamente, enquanto substâncias primeiras, as formas satisfariam um critério substantivo de independência ontológica assimétrica com relação aos objetos dependentes relevantes. Esse critério, [PS], respalda a noção de prioridade definicional como prioridade quanto à definição real.

Agora, quais são as vantagens de [PS] sobre [PE], bem como seus méritos conceituais gerais?

(a) A primeira vantagem é precisamente o último dos pontos que indiquei: embora ela seja muito similar à noção nominal ou linguística de independência assimétrica quanto à definição, a noção de [PS] é nitidamente ontológica. Pois ela captura a intuição de que o que alguns itens são é parte do que outros itens são, ao passo que a recíproca não é o caso. Isso é particularmente importante na estrutura metafísica de Aristóteles como um todo, visto que sustenta a pretensão das formas à substancialidade primeira. Dispondo da noção de [PS], Aristóteles pode argumentar que as essências ou formas não são meramente abstrações do pensamento (como os objetos matemáticos), ou itens linguísticos em termos dos quais outros itens são definidos, ou meramente nossos modos de explicar certos tipos de objetos, compleições ou fenômenos. Antes que isso, elas são partes fundamentais da estrutura do mundo, entidades reais do mundo real que tornam itens ontologicamente dependentes o que eles são por serem as partes mais importantes do que esses itens são. Por essa razão, elas têm que satisfazer o critério ontológico de prioridade - para além do critério definicional - relativamente aos compostos particulares ou tipos de matéria que elas en-formam.

(b) Consoante meu ponto de vista, não é toda e qualquer fórmula definitória ou parte dela que tem sucesso em se referir a uma forma básica do mundo real. Nem é todo e qualquer tipo de item definicionalmente primeiro que satisfaz [PS] e se constitui como substância primeira. [Lembremos nossa discussão de Met. M.2 sobre esse ponto] De fato, por exemplo, algumas práticas definitórias ou relativas à 
definição podem favorecer fórmulas que mencionam certos tipos de matéria, gêneros mais amplos, compleições meramente necessárias, itens extra-essenciais ou não-essenciais que pertencem às coisas definidas. Por exemplo, uma casa poderia ser definida como um abrigo que protege do perigo feito de certos tipos de materiais. Daí, contudo, não se segue que esses itens - por exemplo, tijolos, pedras, etc. - sejam entidades ontologicamente fundamentais ou ingredientes do que as coisas definidas são. De fato, é o inverso que se dá: porque eles tornam os objetos derivativos o que eles são, certas entidades do mundo real são formas substanciais de, e ontologicamente anteriores a, esses objetos. $A$ fortiori, eles são mencionados nas definições daquelas coisas e são anteriores a elas na definição real7. É basicamente 'ser um abrigo de certo tipo' que faz de uma casa a coisa que é, mesmo se sua definição - aliás, mesmo se sua definição real - envolver menção de certos tipos de matariais. Portanto, meu ponto de vista poderia abarcar mesmo tais práticas definitórias e ainda sustentar que nem tudo que é definicionalmente anterior é também ontologicamente anterior.

(c) Os exemplos dados para esclarecer a noção de prioridade ontológica têm sucesso contra o fundamento de [PS].

No exemplo do ângulo agudo de [T3], [PS] liberta Aristóteles do erro que os comentadores lhe atribuem. Um ângulo reto é o que é sem que um ângulo agudo seja o que é, mas não inversamente. Isso é verdade por causa da conexão entre as considerações definicionais e ontológicas.

Tomemos os exemplos fornecidos em [T1]-[C] \& [D].

[T1]-[C] Pois algumas coisas são anteriores em potência, e outras em atualidade, como por exemplo, a metade de uma linha [é anterior] em potência à linha inteira, e a parte ao todo, e a matéria à substância, mas é posterior em atualidade; pois quando o todo for dissolvido, elas serão em atualidade. [D] De certo modo, então, todas as coisas chamadas anteriores e posteriores são ditas ser tais com respeito àquelas últimas; pois para algumas é possível serem sem as outras com respeito ao vir a ser, como, por exemplo, o todo em relação às suas partes, já para outras, [isso é possível] com respeito à destruição, como, por exemplo, a parte em relação ao todo. Igualmente também nos outros casos (tradução de Kirwan ligeiramente modificada). 


\section{8}

Aqui, as noções de prioridade com respeito ao ser em ato e com respeito à geração parecem equivalentes na medida em que ambas são exemplificadas por, por exemplo, todos relativamente às partes. As caracterizações ‘ser em ato' e 'geração' podem ser plausivelmente concebidas como qualificando o modo como os itens anteriores e posteriores são o que são. Em particular, como seres plenamente funcionais (atuais) ou como seres no último dos estágios finais do vir-a-ser (consequentemente, mais próximos da completude ou "perfeição"), a linha inteira e a forma do ser humano (plenamente realizada em um tipo de corpo apropriado) são ontologicamente anteriores a, respectivamente, a metade da linha e o corpo humano, precisamente com respeito ao ser em ato ou geração:

(1) O que é ser uma meia-linha completa ou 'propriamente', 1/2 L, depende do que é ser uma linha inteira completa, 'propriamente' ou 'perfeita', L, mas não inversamente.

$\mathrm{E}$ :

(2) O que é ser um corpo humano plenamente funcional (um exemplo material) depende do que é ser um ser humano plenamente funcional, no qual a forma relevante é plenamente realizada (um exemplo de substância). A recíproca não é verdadeira.

Deve-se enfatizar que as caracterizações 'completo', 'propriamente', 'perfeito', etc., em (1) e 'dissolvido', 'truncado', etc., em (3) não visam assimilar os casos matemáticos aos biológicos. Há uma nítida diferença entre os dois tipos de casos. Ao mesmo tempo, contudo, há uma analogia entre eles. Assim como há algumas instâncias completas ou plenamente funcionais de tipos biológicos, da mesma maneira há alguns símbolos paradigmáticos ou plenamente adequados de tipos matemáticos de entidades. Por exemplo, uma linha particular sem largura e sem profundidade (um comprimento) poderia ser uma tal instância de tipo matemático de linha. Além disso, assim como há algumas instâncias não completas ou não plenamente funcionais de tipos biológicos, assim também há alguns exemplos 'menores' de tipos matemáticos de entidades. Por exemplo, um círculo de bronze seria uma instância menos que paradigmática do tipo matemático de círculo.

É claro agora que o esquema existencial é problemático por razões semelhantes àquelas mencionadas anteriormente. Primeiro, ele não assegura as relações de independência assimétricas desejáveis: um corpo 
humano plenamente funcional não pode existir sem que a forma de um ser humano exista nele e o en-forme plenamente, e reciprocamente. Mais importante, o esquema existencial pode acomodar as caracterizações 'com respeito ao ser em ato' ou 'vir-a-ser' apenas de uma maneira artificial e ad hoc: como entender, por exemplo, a afirmação de que uma linha inteira pode existir em ato sem a metade da linha existir em ato, mas não inversamente, sem reduzir isso a um caso de jargão escolástico vazio? Se, ao contrário, essa afirmação fosse explicada à maneira plausível de (1) e (2), resultaria enganoso ou incorreto também invocar a noção de existência.

Por outro lado, em [T1]-[C] e [D] prioridade com respeito a ser em potência e prioridade com respeito à destruição parecem requerer que alguns itens tenham que ser anteriores ou posteriores a outros apenas como seres incompletos (potenciais) ou como produtos de algum tipo de corrupção. Tipos de candidatos à corrupção poderiam ser, por exemplo, a dissolução completa de algo em suas partes ou a separação de uma parte com respeito a um todo. Assim:

(3) O que é ser uma linha dissolvida ou truncada (de um certo tipo) depende do que é ser um meio-segmento restante ou destacado (do tipo relevante) mas não inversamente.

E:

(4) O que é ser um ser humano que se corrompeu ou foi mutilado depende do que é ser um corpo remanescente ou parte de corpo amputada (do tipo relevante) mas não inversamente.

Assim como um ser humano morto é definido em termos de um corpo remanescente de um certo tipo (por exemplo, um cadáver), assim também no nível ontológico o que deve ser esse tipo de ser humano que se corrompeu depende do que é ser esse tipo de matéria remanescente. Como Aristóteles observa em [T1]-[C], em 1019a10-11, quando um todo ou uma coisa completa e plenamente en-formada (uma linha, um todo ou uma substância) se dissolve em suas partes ou se corrompe, o ser em potência remanescente relevante (um segmento, uma parte, matéria) é em ato o ser em potência ou não funcional remanescente que ele é dito ser (“dialuthentos gar kat' entelecheian estai"). Se assim é, ele é ontologicamente anterior ao todo (o qual não mais é o que é ser um todo completo, plenamente funcional) com respeito ao ser incompleto, potencial, ou, no que nos interessa especificamente aqui, com respeito à corrupção. Por 
outro lado, a abordagem existencial parece falhar mais uma vez. Primeiro, à semelhança dos casos anteriores, ela não pode assegurar o requisito da assimetria. Se se mantiver arraigado ao esquema existencial da prioridade com respeito ao ser em potência ou corrupção, será preciso assumir que um corpo remanescente (por exemplo, o cadáver de Sócrates) pode existir sem que o homem correspondente (Sócrates morto) exista ou tenha existido (mas não inversamente). A primeira opção não parece promissora: pois o cadáver de Sócrates e Sócrates morto implicam reciprocamente a existência um do outro. A segunda opção é obviamente falsa: o 'cadáver de Sócrates' não pode existir sem que Sócrates morto jamais tenha existido. Para dar um derradeiro exemplo: assim como uma parte corporal destacada pode existir (como não-funcional ou destacada) independentemente do homem mutilado, assim também um homem mutilado pode existir (como mutilado ou não plenamente-funcional) independentemente da parte destacada. Segundo, a afirmação de que uma meia-linha pode existir potencialmente sem que a linha inteira exista potencialmente, mas não inversamente, não parece ter qualquer significado satisfatório, a menos que seja entendida da maneira (3) e (4). Mas, se é assim, é preferível empregar a noção de [PS] ao invés de [PE].

(d) A motivação subjacente à minha explicação é que [PS] tem sucesso exatamente onde [PE] falha em provar. Em particular, uma forma não pode ser ontologicamente anterior aos itens de que Aristóteles pensa que ela o é (matéria e compostos) se essa relação é entendida existencialmente. Não obstante, ela tem que ser ontologicamente anterior de alguma maneira, se for uma substância genuína. [PS] fornece a solução requerida para esse impasse. Essa noção não-existencial de prioridade chancela um critério de independência ontológica útil para a substancialidade primeira. Pois, apesar de não serem o tipo de itens que poderiam satisfazer a versão existencial desse critério, as formas são anteriores aos compostos quanto ao ser o que são, e podem servir como substâncias primeiras.

\section{Apêndice: Por que substâncias compostas particulares não se qualificam para prioridade ontológica relativamente a seus atributos não-substanciais.}


Primeiro, é claro que compostos particulares não podem satisfazer [PS] relativamente a seus atributos não-substanciais. Por exemplo, Sócrates pode existir sem ser caminhante e ter outro atributo ao invés de ser caminhante, mas ser caminhante pode igualmente existir sem Sócrates existir e ser um atributo de uma outra substância (por exemplo, Cálias).

Tomar o caminhar de Sócrates como uma propriedade particular que não pode existir à parte dele não resolve o problema. Pois não é claro se Aristóteles aceita nem como ele constrói propriedades particularizadas. Além do mais, mesmo se admitirmos propriedades particularizadas nãosubstanciais no delineamento ontológico da Metafisica de Aristóteles, não é óbvio por que elas devem pertencer a um portador particular antes que outro. Por que uma propriedade peculiar de ser andante - mesmo se especificada até o mínimo detalhe - não pode existir independentemente de Sócrates existir, como exatamente o mesmo atributo particularizado de ser andante que, contudo, pertence a, por exemplo, Cálias? A afirmação de que esse atributo de ser andante não pode existir sem Sócrates existir porque ele é propriedade particularizada do próprio Sócrates não é uma resposta satisfatória. Mais importante, essa resposta não faz frente à questão crucial de por que esse atributo de ser andante não pode pertencer a qualquer outra substância particular ao invés de Sócrates: pois a afirmação de que isso seja assim porque esse atributo pertence somente a Sócrates parece, novamente, uma petição de princípio. A dificuldade básica, a essa altura, é que, embora propriedades particularizadas nãosubstanciais devam pertencer a um portador particular, não há razão para negar que elas possam pertencer a um portador particular ao invés do outro. Seria possível replicar que, por exemplo, a propriedade peculiar de Sócrates de ser andante não pode sequer ser especificada ou referida sem que se mencione o nome próprio ou descrição definida de Sócrates. Isso, no entanto, pode refletir meramente as limitações linguísticas ou epistêmicas de nossos modos de descrever ou nos referir a supostas propriedades particularizadas. Isso não precisa implicar nada sobre as condições de existência ou natureza dessas propriedades elas mesmas.

Além do mais, assim como Sócrates existir é necessário para a existência de uns ou outros atributos acidentais, assim também a existência dos últimos é necessária para Sócrates existir: pois ele não pode existir independentemente de todos os seus atributos acidentais determinados. Igual- 
mente, embora ele possa existir sem uns ou outros atributos acidentais determinados (por exemplo, ele pode existir como pesando $71 \mathrm{~kg}$. ao invés de $70 \mathrm{~kg}$., ou como sendo bronzeado ao invés de pálido), ele não pode existir sem quaisquer atributos acidentais determináveis, tais como ter peso ou ter compleição etc ${ }^{8}$. Parece, então, que substâncias particulares não podem ser anteriores a seus atributos não-substanciais no sentido em que elas poderiam existir sem eles mas não inversamente.

Segundo, substâncias compostas particulares não podem sequer ser anteriores quanto a 'ser o que são' com relação a seus atributos nãosubstanciais. Se alguém pensar que uma substância particular, A, é ontologicamente anterior a seus atributos não-substanciais, Bs, quanto a A ser o que é independentemente de qualquer B dado, ou mesmo de todos os Bs serem o que são, ele se tornará incapaz de preservar o requisito da assimetria. Pois os Bs também são o que são independentemente de A ser o que é: assim como Sócrates é o que é (um homem) independentemente de branco ser o que é (um certo tipo de cor), assim também ser branco é o que é independentemente de Sócrates ser o que é.

Se alguém considerar que substâncias particulares são, 'quanto ao ser o que são', ontologicamente anteriores às propriedades particularizadas nãosubstanciais, encontrará a seguinte dificuldade: por que uma propriedade peculiar de, por exemplo, ser branco, deveria depender de Sócrates ser o que ele é para ser a brancura particular que é? Seria insatisfatório responder que isso é assim porque essa brancura particular pertence somente a Sócrates ou porque o nosso modo de especificar ou se referir a ela envolve (talvez necessariamente) o nome próprio ou a descrição definida de Sócrates. Seria preciso oferecer uma razão mais básica pela qual essa brancura particular ela própria não seria, nem, talvez, poderia ser, a brancura particular que é independentemente de Sócrates ser o que é9 9 .

À luz dessas considerações, seria forçoso concluir que a prioridade não pode aplicar-se a substâncias particulares relativamente a seus atributos não-substanciais se concebida como uma capacidade de ser - ou de existir, ou de ser o que é - sem eles, mas não inversamente. Se assim é, substâncias particulares não podem, parece, satisfazer qualquer requisito de prioridade ontológica do modo [AI].

Se isso é correto, os critérios de primazia das substâncias particulares das Categorias resultam problemáticos no contexto da Metafísica. Por essa 
razão, restringi meu tratamento da prioridade ontológica apenas à Metafísica, já que a pretensão de que a forma seja substância primeira parece mais promissora. Nas Categorias a tese fundamental que ancora a primazia das substâncias particulares é que elas nem são ditas de nem estão em algo como sujeito, por oposição às outras coisas, que ou são ditas de ou estão em substâncias particulares (ou ambos) como sujeitos (Categorias 2, 1b3-6; 5, 2a12-14; 2a34-b5; 2b15-17). Essa tese fundamental de subjacência parece explicar a prioridade ontológica ou independência das substâncias particulares: porque elas são sujeitos básicos desse tipo, é impossível para algo outro ser, se elas não são (2b5-6; cf. b66c). Há dois modos nos quais se pode entender essa afirmação de independência ontológica:

(a) Assimetricamente, acrescentando a cláusula 'mas não inversamente': se substâncias particulares não são, é impossível para algo outro ser, mas se algo outro (assumindo um escopo distributivo fraco) não é, é possível para substâncias particulares ser. Contudo, meus argumentos expostos acima implicam que substâncias particulares não podem, sem problemas, ser ontologicamente independentes de entidades não-substanciais dessa maneira assimétrica, seja em existência, seja em serem o que são.

(b) Simetricamente: assim como algo outro não pode ser, se substâncias particulares não são, assim também substâncias particulares não podem ser, se o resto (assumindo um escopo coletivo forte) não é. Nesse caso, poderia ser argumentado que a prioridade de substâncias particulares é próxima ao quinto tipo de prioridade nas Categorias 12,14b10-23. Esse tipo de prioridade se dá entre itens cujos respectivos seres se implicam um ao outro reciprocamente ou simetricamente: se x é, então y é; e se y é, então x é. Contudo, há uma ulterior relação causal assimétrica entre os relata tal que, por exemplo, o ser de x é a causa do ser de y mas não inversamente. A idéia, então, seria que, conquanto o ser das substâncias particulares e o do resto das coisas se impliquem reciprocamente um ao outro, ainda assim o ser das substâncias particulares funda ou explica, de algum modo, o ser de tudo mais.

Por promissor que possa parecer, esse esquema envolve dificuldades sérias. Primeiro, o que é causado por substâncias particulares, e de que maneira: a existência de tudo mais por sua própria existência ou o 'ser o que é’ de tudo mais por seu próprio ‘ser o que são’? Segundo, qual a noção 
de causa operando nesse tipo de prioridade ontológica? Terceiro, na medida em que há dificuldades quanto ao escopo em todas as formulações de independência apresentadas nas Categorias, resulta ainda mais premente o problema: é por tudo coletivamente ou por qualquer uma das restantes entidades que as substâncias particulares são causalmente responsáveis? Por fim, onde nas Categorias se poderia, se é que se poderia, encontrar expedientes teóricos que, respondendo qualquer uma das questões acima, chancelassem esse tipo de prioridade? De fato, por exemplo, seria permitido apelar à explicação das quatro causas na Física para resolver a segunda questão acima levantada? Todas essas questões mostram que o ponto de vista das Categorias envolve problemas específicos por si mesmo. Para evitar esses problemas, é preferível restringir nossa discussão à Metafísica ${ }^{10}$.

${ }^{1}$ A maioria dos comentadores entende o ponto de vista de Aristóteles da maneira modal.

2 Aristóteles claramente argumenta que as formas são definicionalmente e ontologicamente anteriores tanto aos compostos universais quanto aos particulares: a frase "synolou zôou" em 1035b19 parece referir-se a compostos universais(cf. b27-30), ao passo que "kath' hekaston dê homoiôs" (cf. b19-20)a particulares (cf. b30-31).

3 Annas J., Aristotle's Metaphysics, Books M and N, Oxford, 1976, pp. 94 and 133.

${ }^{4}$ Ross, Metaphysics, vol. 2, p. 415. Cleary, em Senses, p. 89, também considera que a frase "tauta de ouch hama hyparchei" tem que ser tomada como "significando que geralmente dois tipos de prioridade não pertencem conjuntamente à mesma coisa" (grifo de Cleary).

5 Para um uso similar de hama, ver as formulações do Princípio de Não-Contradição em Met. Г. Por exemplo, em Г.3, 1005b19-20 e 26-27, pode-se traçar um sentido de hama que implica que é impossível para dois atributos contraditórios pertencer à mesma coisa consistentemente ("ao mesmo tempo" em um sentido, por assim dizer, lógico).

${ }^{6}$ Penso que essa dificuldade permanece independentemente das três seguintes questões: se substâncias particulares são tomadas como ontologicamente anteriores em existência ou em ser o que são; se elas são pensadas como anteriores a todos ou alguns dos seus atributos nãosubstância; e se os relata posteriores são atributos não-substância universais ou particulares.

7 Mesmo se as definições constituem nossa principal via para obter acesso às formas substanciais, contudo, quanto aos objetos do mundo real, seu ser o que eles são não inclui como partes tais itens linguísticos, definicionais, mas sim as contrapartes ontológicas desses itens.

8 Para esses problemas, ver Burnyeat M. et al., Notes on $Z$ [Z], Faculty of Philosophy, University of Oxford, 1979 , pp. 4-5 e Bostock D., Aristotle: Metaphysics Books $Z$ and $H[Z \& H]$, Oxford, 1994, pp. 58-60. Os dois últimos pontos sugerem que as substâncias particulares de Aristóteles não são meros particulares dos quais os atributos podem ser removidos. De acor-

doispontos, Curitiba, São Carlos, vol. 7, n. 3 - especial, p.11-36, abril, 2010 
do com alguns comentadores (Charlton, Aristotle's 'Physics' I, II, Oxford, 1970, pp. 136-8; Gill M. L., Aristotle on Substance: The Paradox of Unity [Substance], Princeton, 1989, pp. 26-31; Maudlin T., 'Substances and Space-Time: What Aristotle Would Have Said to Einstein', Studies in the History and Philosophy of Science, 21, pp. 532 and 534-6), em Met.Z.3, parece haver a pretensão de que não se pode 'descartar' todos os atributos de um sujeito. $O$ requisito de independência ontológica de Aristóteles não pode violar as cláusulas de Z.3, pois, caso contrário, o absurdo da matéria prima se seguiria. Esse absurdo não está desvinculado da impossibilidade de meros particulares. Maudlin (pp. 538-9) sustenta que a reductio do argumento de Aristóteles em Z.3 mostra que tanto a matéria prima quanto meros particulares são as 'monstruosidades gêmeas da metafísica'. Em Z.3 o argumento de Aristóteles é dirigido primeiramente contra a matéria prima, mas pode igualmente bem aplicar-se a meros particulares. A premissa básica desse argumento, que torna tanto a matéria prima quanto os meros particulares impossíveis é que há alguns atributos que são essenciais para a existência e o ser de um sujeito: nem todos os atributos podem ser removidos dele.

${ }^{9}$ Creio que não preciso responder a questões desse tipo, visto que não vejo razão para tratar das ropriedades particularizadas não-substância na discussão da Metafísica.

10 Há uma outra razão para esse tipo de restrição. Na Metafísica, o próprio Aristóteles parece refinar ou talvez enfraquecer a centralidade da noção de subjetividade das Categorias como um critério para a substancialidade primeira ou como fundamento para a primazia ontológica das substâncias. Pois na Metafísica, ao que parece, ele qualifica a noção de subjetividade em termos de ser um isto, separação, e prioridade ou mesmo favorece esses três critérios em detrimento da subjetividade.Ver, por exemplo, Met. Z.3, 1029a5-10; 26-30.Ver também Gill, Substance, p. 31.

\section{Referências bibliográficas}

ANNAS, Julia. Aristotle's Metaphysics - Books M and N. Oxford:

Oxford University Press, 1976.

BOSTOCK, David. Aristotle's Metaphysics - Books $Z$ and H. Oxford:

Oxford University Press, 1994.

BURNYEAT, M. F. et al. Notes on Zeta, Study Aids, Monograph no 1.

Oxford, Sub-faculty of Philosophy, 1979

CHARLTON, William. Aristotle's Physics - Books I and II. 2a ed.

Oxford: Oxford University Press, 1992 [1970].

CLEARY, J. Aristotle on many senses of priority, Albany: SUNY Press. 1988.

GILL, Mary Louise. Aristotle on substance - The paradox of unity.

Princeton: Princeton University Press, 1989. 
MAUDLIN, T., 'Substances and Space-Time: What Aristotle Would Have Said to Einstein', Studies in the History and Philosophy of Science, 21, pp. 532 and $534-6$

ROSS. D. Aristotle's Metaphysics - revised text with introduction and commentary. Oxford: Clarendon Press, 1924. 